\title{
STATISTICAL VALIDATION OF THE EFFECT OF LATERAL LINE LOCATION ON PAVEMENT MARKING RETROREFLETIVITY DEGRADATION
}

\author{
MAJOR W. NEIL CRAIG III \\ MAJOR WILLIAM S. SITZABEE, PE \\ DR. WILLIAM J. RASDORF, PhD, PE \\ DR. JOSEPH E. HUMMER, PhD, PE \\ NORTH CAROLINA STATE UNIVERSITY \\ DEPARTMENT OF CIVIL, CONSTRUCTION, AND ENVIRONMENTAL \\ ENGINEERING
}

\begin{abstract}
:
This effort examined the effect of lateral location on the degradation of retroreflectivity in thermoplastic pavement marking systems. The study examined data collected on North Carolina roads over a five-year period and conducted a statistical analysis to determine if there was a significant difference in the rates of retroreflectivity degradation between edge lines and center lines. The study concluded that there was statistical evidence that lateral line location does have an effect on retroreflectivity degradation and that center lines degrade faster than edge lines. Understanding retroreflectivity performance over time facilitates the development and implementation of guidelines and tools that will be used for holistic asset management. Based on our findings, we recommend changes in pavement marking maintenance strategies.
\end{abstract}

Keywords:

Pavement markings, retroreflectivity, degradation rates, management 


\title{
IMPACT OF LINE LOCATION ON THERMOPLASTIC PAVEMENT MARKING RETROREFLECTIVITY DEGRADATION
}

\author{
INTRODUCTION \\ SCOPE \& OBJECTIVE \\ BACKGROUND \\ Pavement Marking Materials \\ Retroreflectivity Measurement and Standards \\ Retrorefelctivity Measurement Devices \\ Types of Lane Markings \\ Previous Research \\ South Carolina Study \\ NCHRP Synthesis \\ METHODOLOGY \\ Data Collection \\ Data Reduction \\ Average Value Analysis \\ Analysis of Variance \\ $\underline{\text { RESULTS }}$ \\ Overall Summary Statistics \\ Average Value Analysis (Un-weighted) \\ Average Value Analysis (Weighted) \\ Analysis of Variance (Un-weighted) \\ Analysis of Variance (Weighted) \\ Comparison to Current Literature \\ CONCLUSIONS \\ RECOMMENDATIONS \\ REFERENCES
}




\section{INTRODUCTION}

The NC Department of Transportation (NCDOT) is charged with managing all aspects of a 78,000-mile roadway system, which includes over 312,000 lane miles of pavement markings [Howard, 2006]. Pavement markings cost NC approximately $\$ 14.5$ million a year in contractor-performed work which represents two percent of the $\$ 700$ million NCDOT annual budget [Howard, 2006]. Strategic approaches to pavement marking management will not only ensure efficient use of a limited budget but will enable NCDOT to follow Federal guidance in asset management.

According to the Federal Highway Administration (FHWA), asset management is a strategic approach to managing physical infrastructure using cost-effective solutions based on sound engineering and business principles [Cambridge Systems, Inc., 2002]. Asset management should consider both short-term and long-term system needs using a holistic, life-cycle approach. NCDOT is taking steps to improve pavement marking infrastructure management in order to meet projected Federal minimum pavement marking retroreflectivity requirements. These steps include shaping their asset management strategy based on the guidelines and principles set forth in FHWA's Asset Management Guide [Cambridge Systems, Inc., 2002].

Section 406 of the United States Department of Transportation and Related Agency Appropriation Act of 1993 directed the Secretary of Transportation to revise the Manual on Uniform Traffic Control Devices (MUTCD) to include a minimum standard of retroreflectivity for pavement markings [United States Congress, 1993]. This Congressional directive applies to all roads that are open to the public. The Federal Highway Administration (FHWA) published the regulation 69 FR 45623 on 30 July 2004 and included directives for sign retroreflectivity but did not include the minimum required retroreflectivity for road pavement markings. Candidate minimum values for road pavement markings have been established [Turner, 1998], and the FHWA is expected to publish pavement marking retroreflectivity standards in the near future.

\section{SCOPE \& OBJECTIVE}

This paper focuses on the impact of lateral line location on pavement marking degradation over time. Previous studies have validated that color, material type, and surface type all impact pavement marking degradation. Current literature indicates that color, pavement surface, and material type, are all valid independent variables, which do affect the rate of change in pavement marking performance. However, the affect of lateral line location remains a question.

It is a common assumption that the lateral location has an effect on the rate of retroreflectivity degradation, and that the center line or center skip lines will degrade faster than edge lines due to traffic. However there is no evidentiary validation of this statement available in current literature. Specifically, this research used statistical analysis to determine whether lateral line location was a significant factor to be considered in degradation of pavement marking retroreflectivity. 
This paper will quantify the statistical significance of lateral line location on pavement marking degradation and presents the management implications. As will be discussed, the data used for the analysis was from a study conducted over a five-year period in NC and the analysis focused solely on yellow and white thermoplastic markings on an asphalt base course.

This study is one component of a larger study to determine long-term performance characteristics of pavement markings in $\mathrm{NC}$ and provide an asset management strategy. NCDOT has determined that it needs to develop an optimized pavement marking strategy that is performance based in order to maximize cost savings and prepare to comply with the impending Federal Highway standards. Data driven analysis, as advocated by Wilson-Orndoff, lays the foundation for using quantifiable measures to formulate pavement marking asset management strategies [2003]. The objective at the NCDOT is to formulate a pavement marking performance model that can accurately predict the life cycle of pavement markings and then use this in an asset management framework to accurately determine when each segment of road needs to be remarked. As previously determined, improvements in pavement marking quality is directly correlated with reduced probability of an accidents [Al-Masaeid and Sinha, 1994].

\section{BACKGROUND}

Previous research by others focused on the impact of pavement marking retroreflectivity on a driver's visibility and how pavement markings degrade over time. Understanding retroreflectivity performance over time is important to establishing a pavement marking strategy that maximizes the material's lifecycle by minimizing replacement of pavement markings that still have sufficient retroreflectivity. There is a gap in the current knowledge of how the lateral line location affects the rate of degradation. This section provided a basic description of pavement marking materials and retroreflectivity measurement, and highlights two previous studies on pavement markings.

\section{Pavement Marking Materials}

According to the American Association of State Highway and Transportation Officials (AASHTO, 2004), pavement markings are defined as center stripes, lane lines, nopassing barriers, and edge striping. In all cases pavement markings refer to long-lines and should not be confused with object markings or delineators. The term lateral line location deals with the transverse location of the line along the pavement.

Pavement markings are first classified as durable and non-durable. Non-durable materials are expected to have a service life of one year or less, while durable materials should have a service life greater than one year. Non-durables are typically considered to be paint-based markers while most other materials fall under the durable classification. Table 1 lists the most common materials used in pavement markings across the US [Migletz \& Graham, 2002]. The most common pavement marking material is paint, which is typically replaced annually, based on need and transportation department budget cycles. The second most common material is a raised thermoplastic coating that is laid on top of the base material. Other common materials are polyesters and epoxy. The four 
materials currently in use by the NCDOT are paint, thermoplastics, epoxy, and polyurea. These are shaded in Table 1.

Table 1. Pavement Marking Materials

\begin{tabular}{||c|l|c|}
\hline & Pavement Marking Material Type & Percentage of Use \\
\hline \hline 1 & Waterborne paint & 59.9 \\
\hline 2 & Thermoplastics & 22.7 \\
\hline 3 & Conventional solvent paint & 6.5 \\
\hline 4 & Polyester & 3.8 \\
\hline 5 & Epoxy & 2.7 \\
\hline 6 & Preformed tape - flat & $<1.0$ \\
\hline 7 & Preformed Tape - profiled & $<1.0$ \\
\hline 8 & Methyl methacrylate & $<1.0$ \\
\hline 9 & Thermoplastics profiled & $<1.0$ \\
\hline 10 & Polyurea & $<1.0$ \\
\hline 11 & Cold applied plastics & $<1.0$ \\
\hline 12 & Experimental & $<1.0$ \\
\hline 13 & Green lite powder & $<1.0$ \\
\hline 14 & Polyester profiled & $<1.0$ \\
\hline 15 & Tape removable & $<1.0$ \\
\hline 16 & HD-21 & $<1.0$ \\
\hline
\end{tabular}

[Adapted from Migletz and Graham, 2002]

[Highlighted materials are currently in use in $\mathrm{NC}$ ]

Some state departments of transportation are leery of collecting quantifiable measurements of the condition of public infrastructure so as not to be exposed to tort liability [Baker and Lambert, 2001]. Vereen noted the importance of measuring retroreflectivity in order to possibly mitigate potential civil claims against state departments of transportation. However, without a comprehensive plan to measure and maintain all roads cyclically, it may leave the departments of transportation open to higher liability in the interim. In other words it might be better not to do it at all from a lawyers point of view. A record that the state knew that a certain road sign had a low retroreflectivity value is a plaintiff lawyers dream [Vereen et al, 2004]. Collecting and analyzing data is a key step in developing performance based asset management strategies.

Pavement marking materials themselves provide a base line of retroreflectivity. However, the bulk of the retroreflectivity is achieved through the addition of glass beads embedded into the pavement marking material. Figure 1 illustrates the basic concept of retroreflectivity and shows how the light from a vehicle's headlights is retroreflected off of a glass bead in the pavement marking back to the driver's eye [ASTMa, 2005]. 


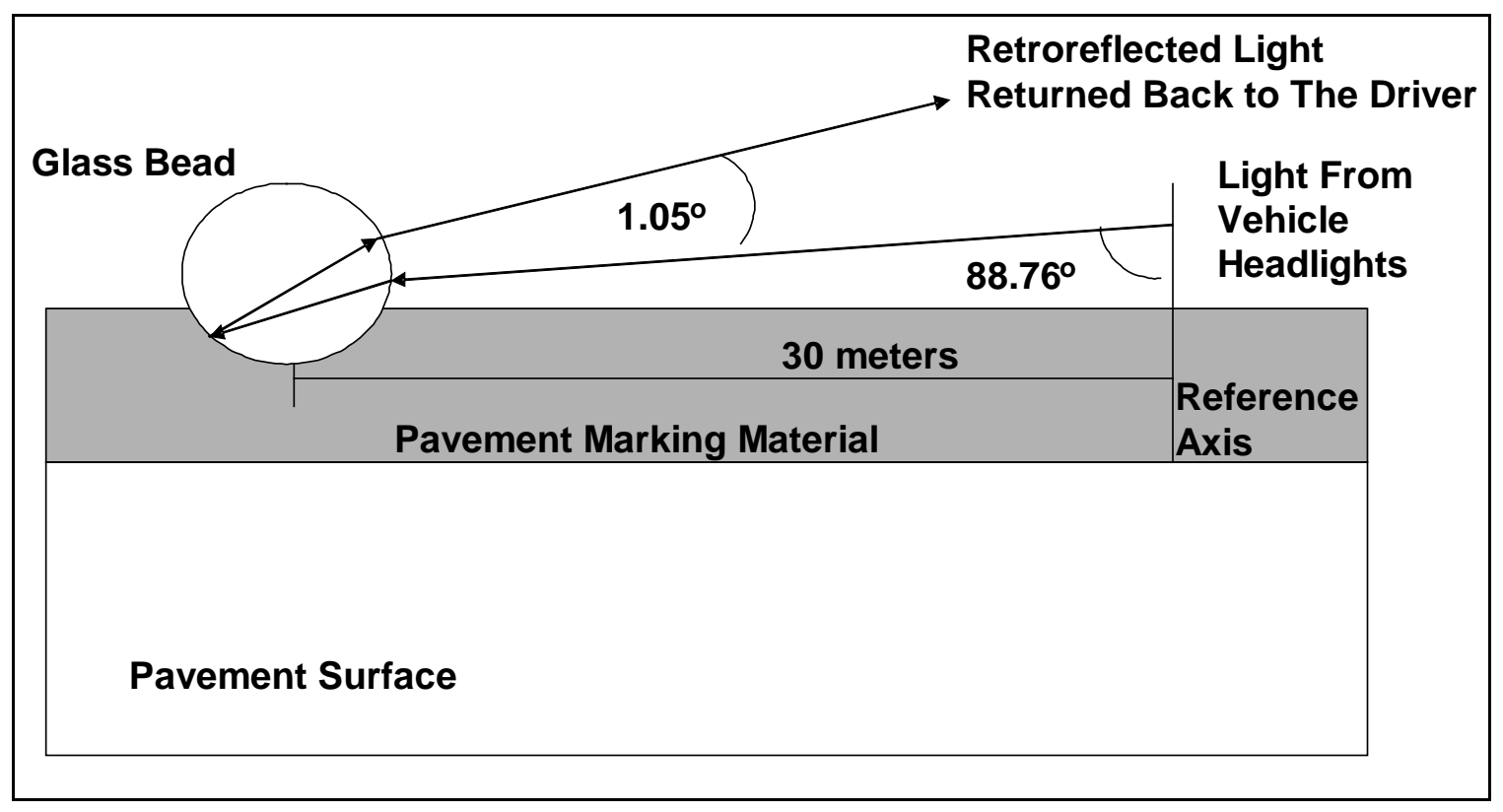

Figure 1. Basic Principles of Pavement Marking Retroreflectivity

\section{Retroreflectivity Measurement and Standards}

The American Society for Testing Materials (ASTM) standard number E1710-05 describes the testing standards using portable retroreflective measurement devices to measure pavement-marking retroreflectivity, which is quantified by the coefficient of retroreflected luminance $\left(\mathrm{R}_{\mathrm{L}}\right)$ in units of millicandles $/ \mathrm{m}^{2} / \mathrm{Lux}\left(\mathrm{mcd} / \mathrm{m}^{2} / \mathrm{lx}\right)$ [ASTMa, 2005]. Current ASTM standards require a specific geometry commonly called the 30meter geometry, which is designed to measure the retroreflectivity at a point 30 meters ahead of a vehicle. This is believed to be the point at which most drivers observe the roadway at night. Figure 1 was adapted from ASTM E 808 and shows the basic geometry required to evaluate retroreflectivity at 30-meter geometry [ASTMb, 2005].

A retroreflectivity test is conducted using a handheld measuring device, which directs light onto the pavement marking, and measures the amount of light reflected back into the device. Light is directed onto the pavement marking at an entrance angle of 88.76 degrees measured from the reference axis, which is the vertical line perpendicular to the pavement surface. The amount of reflected light is measured at an observation angle of 1.05 degrees, which is the difference required for light to reflect back from the headlight to the driver's field of vision based on a spot 30 meters in front of the driver's vehicle.

Additionally, ASTM E 808 requires that all new pavement-marking materials have a minimum retroreflectivity value of $\mathrm{R}_{\mathrm{L}}$ equal to $250 \mathrm{mcd} / \mathrm{m}^{2} / \mathrm{lux}$ for white markings and an $\mathrm{R}_{\mathrm{L}}$ equal to $175 \mathrm{mcd} / \mathrm{m}^{2} /$ lux for yellow markings [ASTMb, 2005].

\section{Retrorefelctivity Measurement Devices}

Six retroreflectometers were evaluated by the Highway Innovative Technology Center (HITEC) and represent the six leading units used by transportation agencies [Texas 
Transportation Institute, 2001]. Four of the six units were handheld devices and two were mobile units. All the units that were evaluated used 30-meter geometry to measure retroreflectivity. The Mirolux 12 was also evaluated but was left out of this summary because it uses 15-meter geometry, which is no longer acceptable under ASTM standards. The four handheld units evaluated were LTL 2000, MX30, MP-30, and FRT01. The two mobile units evaluated were the ECODYN and the Laserlux.

According to the HITEC summary, field tests verified that all six devices produce reliable results for measuring pavement marking retroreflectivity [Texas Transportation Institute, 2001]. The HITEC evaluation indicated that each unit comes with different capabilities and transportation agencies should evaluate the cost verses capability before deciding on which unit would be best to purchase for that agency. Ultimately, any of the six retroreflectometers mentioned would produce viable results [Texas Transportation Institute, 2001].

Handheld verses mobile collection methods each have advantages and disadvantages as well. The handheld units are inexpensive but require a large crew for safety reasons in order to collect a small number of samples. Mobile devices are significantly more expensive but provide for a safer collection method and can collect continuous data throughout the system at highway speeds.

South Carolina conducted statisitcal tests on handheld and mobile collectin devices [Sarasua et. al., 2003]. The study evaluated handheld and mobile collection devices from a repeatability and reproducability standpoint. The analysis found good correlation between handheld units. Additionally, the study concluded that although the fit was not as good between handheld units and the mobile devices that trends were still apparent. Specifically, the study concluded that both the handheld units and mobile device were capable of grouping retrorefelctivity readings into low, medium, and high ranges. This was presented as a significant finding from a human factors stand point since slight variabtions in retrorefelctivity is not noticeable to the driver [Sarasua et. al., 2003].

\section{Types of Lane Markings}

For the purposes of this paper, edge lines are defined as either the white edge line found on the outer edge of both primary and secondary roads, or as the yellow edge line that is found in the middle of a divided primary road, usually marking a raised median. Center lines are defined as the white skip lines found dividing parallel lanes on a primary road or as the yellow skip lines or yellow center lines that divide opposing lanes on a secondary road. Figures 2 and 3 show common lane marking systems for divided four-lane and undivided two-lane roads, respectively. 


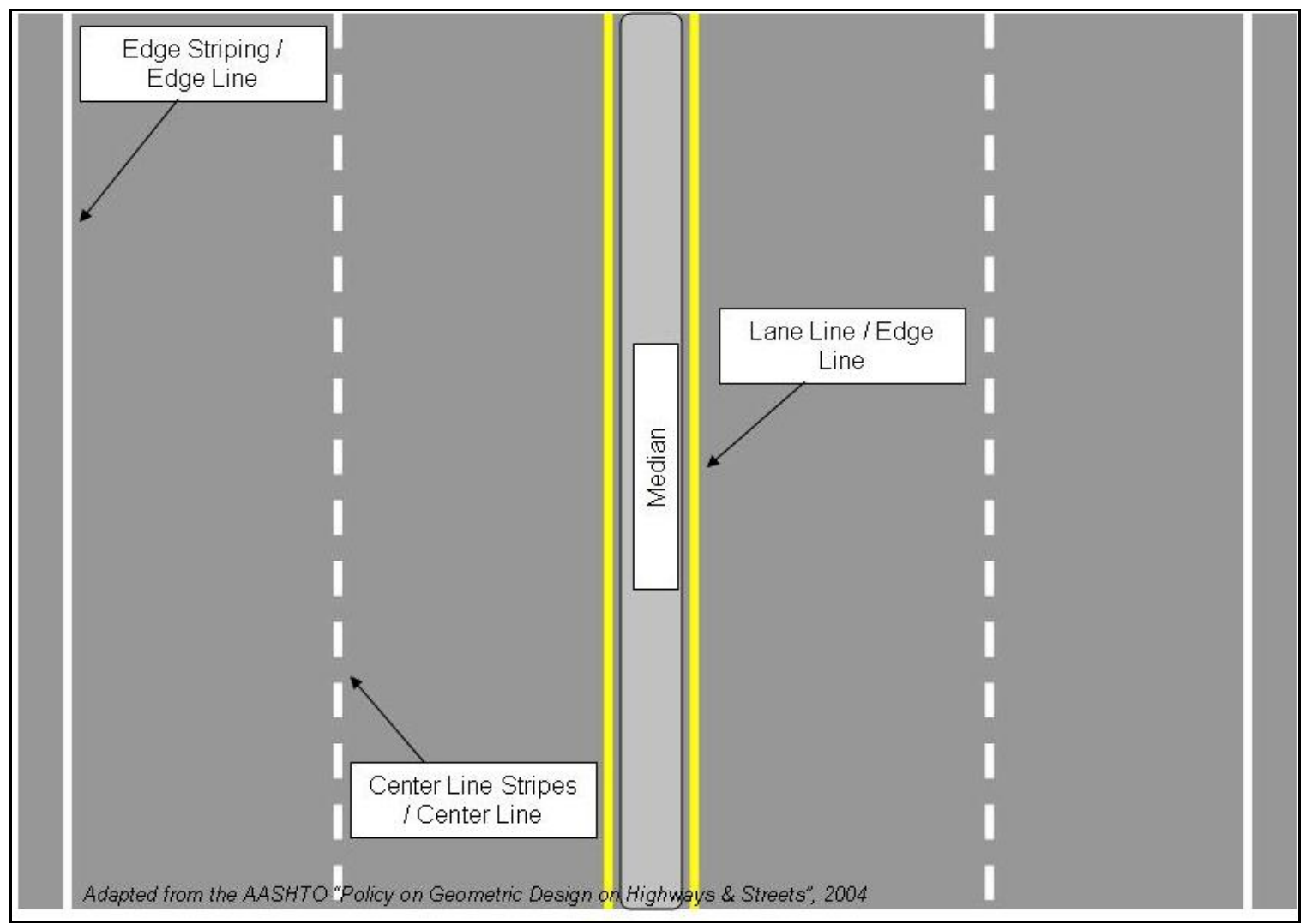

Figure 2. Pavement Markings on a Divided Four-lane Road 


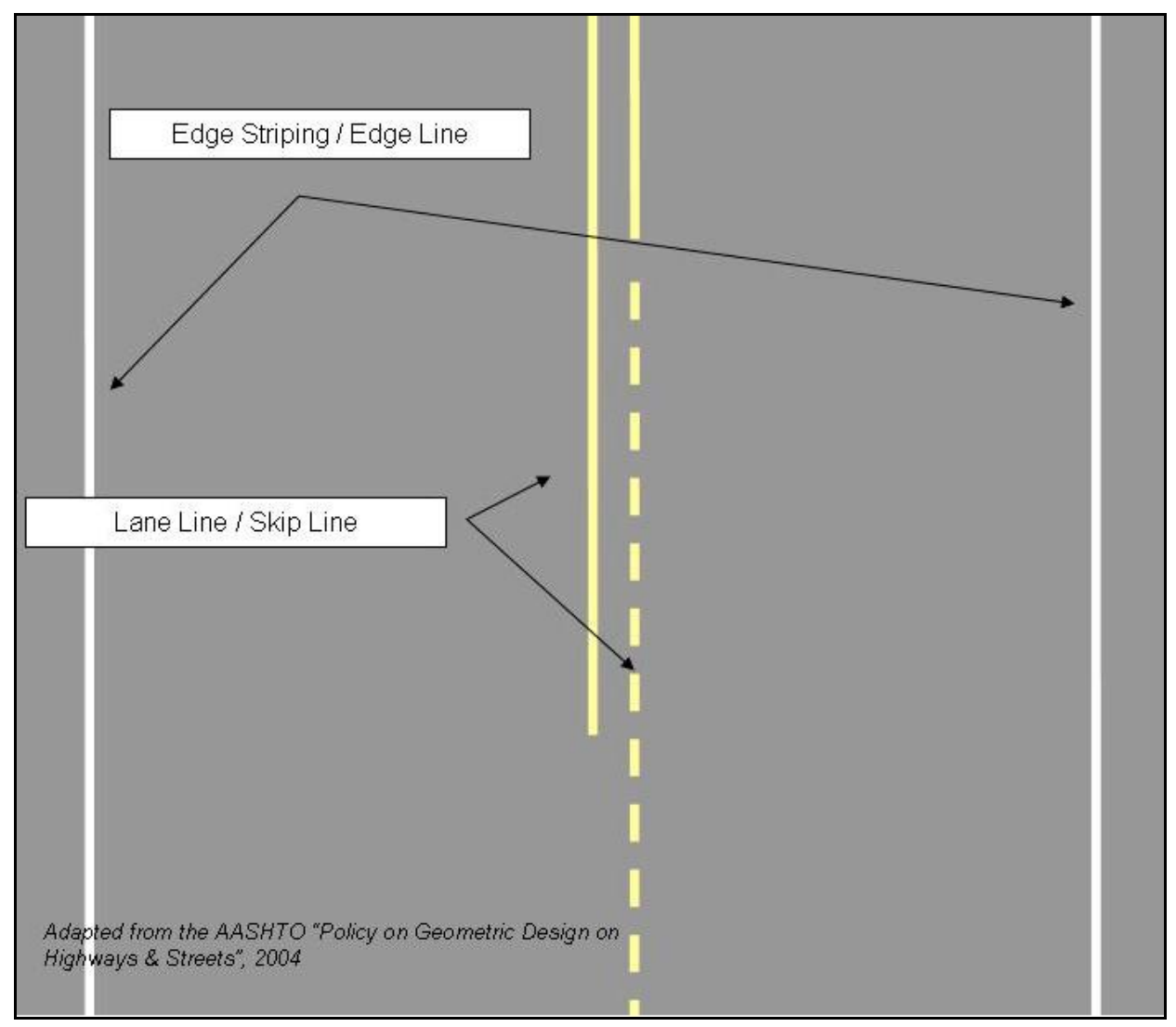

Figure 3. Pavement Markings on an Undivided Two-lane Road

\section{Previous Research}

There are two previous studies that are closely related to this one. The first study was sponsored by the South Carolina Department of Transportation (SCDOT) and published in 2003. It dealt with pavement marking degradation and examined the effects of surface type, marking material, marking color, and maintenance activities on markings. The second study was conducted by the National Cooperative Highway Research Program (NCHRP) from 1994 to 1998. It examined long-term pavement marking practices from across the nation. Both of these studies are examined in detail.

\section{$\underline{\text { South Carolina Study }}$}

SCDOT supported a research project at Clemson University and The Citadel to evaluate the effective life cycle of pavement marking retroreflectivity over time [Sarasua, et. al., 2003]. This study was a response to the need of SCDOT for a pavement marking management strategy based on material performance. Additionally, SCDOT felt that a better understanding of pavement marking management was needed in order to comply with the expected implementation of new FHWA pavement marking minimum retroreflectivity standards. Their primary research objective was to develop predictive models that could estimate the rate of pavement marking degradation. These models could then be applied to an overall pavement markings management strategy. 
The project focused on SC interstate highways and evaluated pavement marking retroreflectivity performance during a 28-month period. Data were collected 6 times during this period at over 150 sites throughout SC's interstate system. An average value was established for each time at each site from a series of 11 measurements taken with a handheld LTL-2000 retroreflectometer. Other retroreflectivity measurement devices were used during the research but only the data from the LTL-2000 were used in the analysis. Furthermore, researchers collected the data using a 30-meter geometry, as required in ASTM E 1710-97 [ASTMa, 2005].

During the data analysis portion of the research, retroreflectivity performance was determined using four major independent variables: surface type, marking material, marking color, and maintenance activities. Each variable was analyzed using regression analysis and was compared to the dependent variables. The dependent variables were the difference in $\mathrm{R}_{\mathrm{L}}$ values between two successive time periods, and the percent difference between the two successive time periods. Using these as dependent variables helped to account for the large variation across the data set. Several other independent variables were considered but only these four were determined statistically significant in their effect on the performance of the pavement markings over time. Traffic volume was one variable that was initially thought to impact performance but was later determined not to.

Traffic volume was inversely correlated to the dependent variable of time and was adequately accounted for as time elapsed. Because time and traffic were directly related and traffic volumes remain relatively constant over the long term, traffic was accounted for in the time analysis. The analysis resulted in the development of three predictive patterns that demonstrate how SC interstate highway marking materials perform over time. All three patterns are shown in Figures 5, 6, and 7 below. Note that units are not specified in these figures. They are only intended to show the general nature of the curve.

The first pattern, shown in Figure 4, demonstrates that the retroreflectivity of new pavement markings increased non-linearly during some initial time period after installation [Sarasua et. al., 2003]. This was due to a greater number of reflective beads being exposed as the marking began to initially wear. After this preliminary time period, retroreflectivity was found to decrease linearly over time with a slight asymptotic curve at the end [Sarasua et. al., 2003].

The second pattern, shown in Figure 5, illustrates retroreflectivity degradation for existing pavement markings [Sarasua et. al., 2003]. The initial value of the retroreflectivity for existing pavement marking systems was typically lower than for new markings and there was a noticeable absence of the initial upward increase in retroreflectivity values.

Finally, the last pattern, shown in Figure 6, followed the same trends as the first two models but with a noticeable shift in retroreflectivity values that was caused by maintenance activity [Sarasua et. al., 2003]. The shift was observed in two different ways based on the type of maintenance activity performed. First, a re-striping 
maintenance activity would reset the retroreflectivity value back to the retroreflectivity value of a new marking and then the curve would follow the same trend as the first model. Second, snowplowing caused a noticeable shift downward in the curve at the time the snowplowing occurred but the curve maintained the same linear downward trend after the activity was finished.

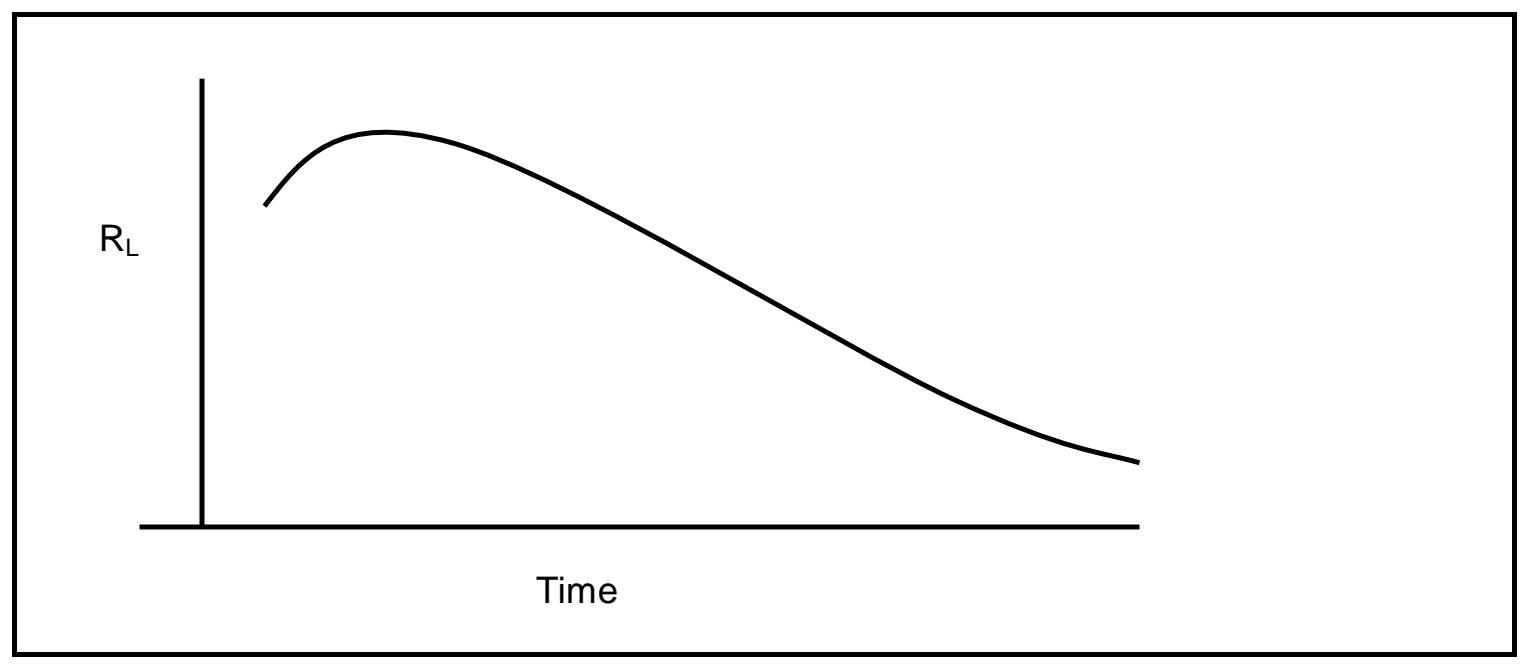

Figure 4. Predictive Trends for Newly Placed Pavement Marking

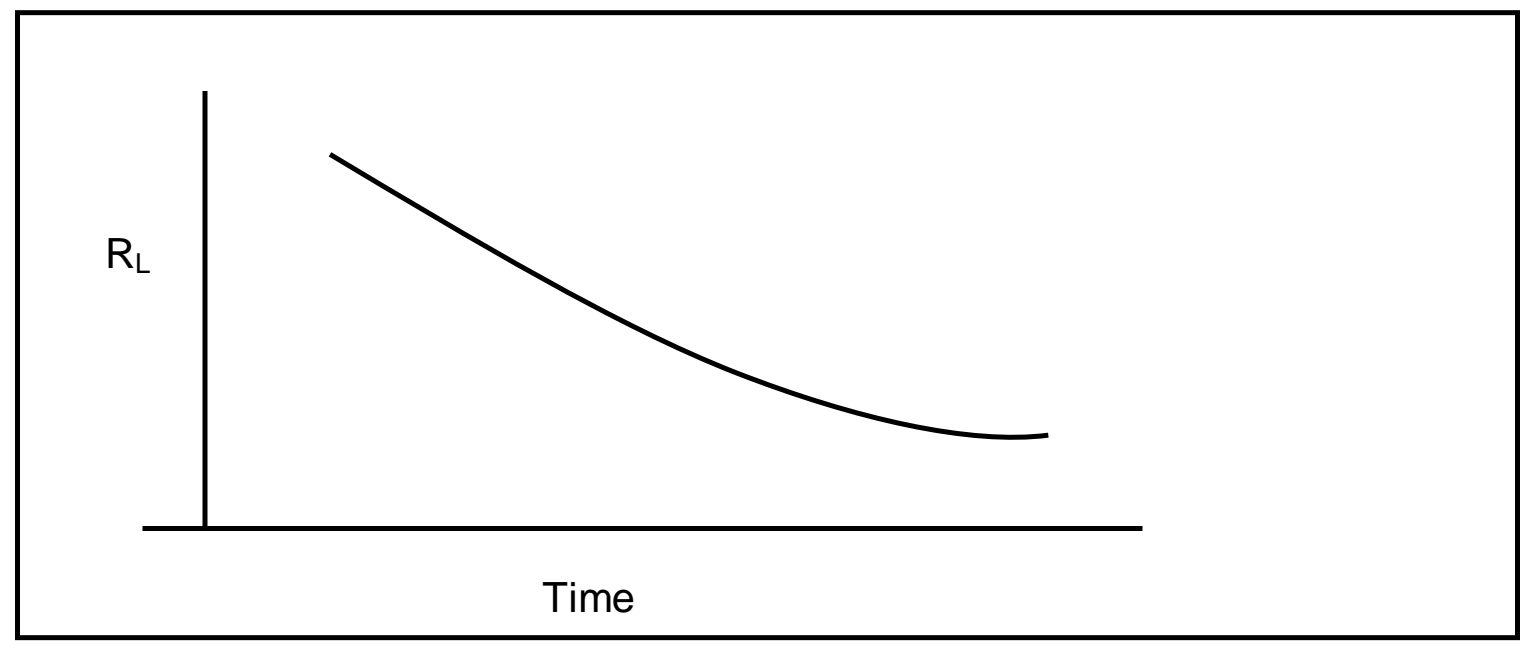

Figure 5. Predictive Trends for Existing Pavement Markings 


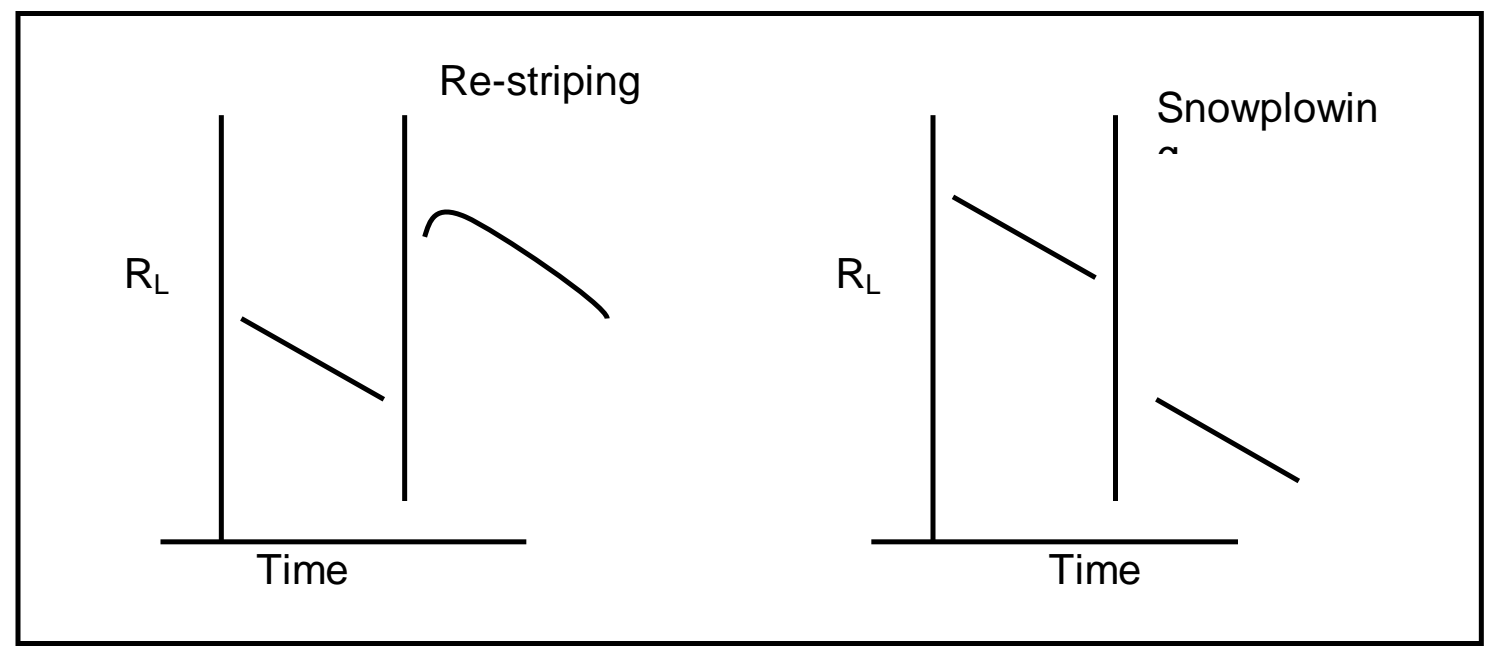

Figure 6. Predictive Trends for Remarking and Snowplowing

\section{NCHRP Synthesis}

The NCHRP synthesis study took place from 1994 to 1998 [Migletz, et al., 2001] and its purpose was to evaluate the life of durable pavement markings. Limited evaluations of some waterborne paints were included in the study as a benchmark. The study collected data on 362 longitudinal (edge, center, \& lane) pavement-marking lines from 85 sites across 19 states. The study collected data on 13 thermoplastic sites and the lengths ranged from 1 to 50 miles.

The NCHRP study used regression analysis to evaluate various materials and establish a predictive degradation curve of the material performance over time. Marking material type, road surface type, and marking material color were the independent variables evaluated. These were the same variables addressed in the SC study. Only maintenance activities were omitted from the FHWA study.

Results from the regression analysis indicate there was a great deal of variation in identical materials at different sites. The variation was attributed to differences in roadway type, region of the country, marking specifications, quality control, and winter maintenance. However, no comments were provided regarding the current age of the pavement markings when the study was performed. Thus, no statistically valid conclusions could be drawn. Still, the analysis did indicate that yellow lines performed better than white. Migletz attributed this to the use of a lower threshold of material expectations rather than to superior performance. Table 2 shows as summary of the results of the Migletz study.

In a follow up study, [Migletz et. al. 2001] established a service life matrix that provides degradation rates sorted by cumulative traffic passages (CTP) and elapsed months. Table 3 , is an adaptation of this matrix and shows the average service life for each material type in months. The matrix is sorted by line color and type of marking material and provides an average service life and standard deviation in months. Additionally, the matrix gives a 
service life range in months. There is a large amount of deviation in the average service lives of the materials listed. Since this data collection spanned 19 different states, this variation was a product of regional diversity in traffic and weather conditions.

Nationally, the two most commonly utilized pavement-marking materials are waterborne paints and thermoplastics. Paints make up approximately 60 percent and thermoplastics make up approximately 23 percent (total $83 \%$ ) [Migletz and Graham, 2002]. From Table 3 we see that the average service life for these is as follows:

- 10.4 months for waterborne paint

- 26.2 months for white thermoplastics

- 27.5 months for yellow thermoplastics.

Table 2 summarizes all of the key parameters and findings of the NCHRP study. In particular, the variability in service life was drastic, as one can see from table 3 . The remaining findings have been discussed.

Table 2. NCHRP Study Summary

\begin{tabular}{|c|c|}
\hline Objective & Develop retroreflectivity degradation rates for roadway pavement markings \\
\hline $\begin{array}{l}\text { Important } \\
\text { Parameters }\end{array}$ & $\begin{array}{ll}\text { - } & \text { Study was from 1994-1998 } \\
\text { - } & \text { Data were collected from } 85 \text { sites across } 19 \text { states } \\
\text { - } & \text { Used a mobile collection device (Laserlux with 30-m geometry) } \\
\text { - } & \text { Study focused on various durable pavement markings } \\
\end{array}$ \\
\hline Key Findings & $\begin{array}{l}\text { - Large variations in the shape of the degradation curves } \\
\text { - } \quad \text { Regional changes influenced the shape of the curve for identical materials, and } \\
\text { line type } \\
\text { - } \text { Matrix of service life degradation rates established based on unpublished data } \\
\text { - } \text { Average Life of waterborne paint is } 10.4 \text { months } \\
\text { - } \text { Average Life of thermoplastics is } 26.2 \text { months } \\
\text { - } \quad \text { Average Life of polyurea is } 24.7 \text { months }\end{array}$ \\
\hline
\end{tabular}


Table 3. Pavement Marking Accepted Service Life Matrix

\begin{tabular}{|c|c|c|c|c|}
\hline \multirow[t]{2}{*}{ Material } & \multirow{2}{*}{$\begin{array}{l}\text { No of Pavement } \\
\text { Marking Lines }\end{array}$} & \multicolumn{3}{|c|}{ " Service Life In Elapsed Months } \\
\hline & & Average & Standard Dev & Range \\
\hline \multicolumn{5}{|l|}{ White Lines } \\
\hline Waterborne Paint & 3 & 10.4 & 7.3 & $4.1-18.4$ \\
\hline Epoxy & 18 & 23 & 17.1 & $1-56$ \\
\hline Methyl methacrylate & 7 & 14.4 & 7.6 & $6.8-29.3$ \\
\hline $\begin{array}{l}\text { Methyl methacrylate } \\
\text { Profiled }\end{array}$ & 9 & 21 & 13.4 & $7.8-43.2$ \\
\hline Polyester & 5 & 24.7 & 7.9 & $14.7-34.1$ \\
\hline Polyester - Profiled & 1 & 45.9 & - & $45.9-45.9$ \\
\hline Thermoplastics & 19 & 26.2 & 14.1 & $7.4-49.7$ \\
\hline $\begin{array}{l}\text { Thermoplastics - } \\
\text { Profiled }\end{array}$ & 14 & 23.8 & 12.8 & $4.7-55.7$ \\
\hline Preformed Tape & 11 & 27.4 & 13.6 & $11.7-60.0$ \\
\hline \multicolumn{5}{|l|}{ Yellow Lines } \\
\hline Epoxy & 15 & 34.3 & 14.6 & $12.6-57.8$ \\
\hline Methyl methacrylate & 4 & 16.8 & 4.2 & $12.6-20.5$ \\
\hline $\begin{array}{l}\text { Methyl methacrylate } \\
\text { Profiled }\end{array}$ & 5 & 25.0 & 6.0 & $18.1-32.8$ \\
\hline Polyester & 2 & 43.8 & 5.8 & $39.7-47.9$ \\
\hline Polyester - Profiled & 1 & 39.6 & - & $39.6-39.6$ \\
\hline Thermoplastics & 10 & 27.5 & 12.1 & $11.0-41.6$ \\
\hline $\begin{array}{l}\text { Thermoplastics - } \\
\text { Profiled }\end{array}$ & 8 & 26.7 & 10.3 & $17.8-50.7$ \\
\hline Preformed Tape & 7 & 30.6 & 11.9 & $19.6-53.4$ \\
\hline
\end{tabular}

[Adapted from Migletz et. al. (unpublished 2000), test without roadway lighting and raised retroreflective pavement markers]

\section{METHODOLOGY}

This section presents the methodology used for data collection and analysis in this study. An independent contractor hired by the NCDOT to measure retroreflectivity for specified $\mathrm{NC}$ roads collected the data for this study. The available data set was reduced to only those roads that used thermoplastic pavement markings. Furthermore, for the initial analysis, only those roads that had been under observation for a full five years were used.

First, an average value analysis was used to establish the initial findings using both weighted and un-weighted averages. Second, an analysis of variance (ANOVA) was used to confirm these findings with a more sophisticated statistical test. The ANOVA test method allowed use of the data from roads that had not yet been observed for the full five-year period, thus giving us a larger sample set to analyze.

\section{Data Collection}

The NCDOT hired a contractor, Precision Scan LLC, to collect retroreflectivity data on specified NC roads using a mobile platform that could collect a large amount of data in a safe and efficient manner. The data were originally collected for quality control and 
quality assurance purposes to ensure the initial retroreflectivity values were as specified [McDiarmid, 2001]. The data collection effort took place from June 1999 through June 2006 and resulted in the collection of nearly 30,000 lane miles of data throughout N.C. Using the mobile device ensured that the data was taken over a broad portion of the road surface instead of just a single spot. NCDOT felt that eliminating the need for a technician to choose a specific spot, as is required with a handheld device, ensured that the collection remained objective.

The data collection device used in this study was a modified Laserlux mobile retroreflectometer mounted on a Chevy Suburban. Currently, ASTM standards are not published for measuring retroreflectivity using a mobile collection device but proposed methods are currently under review. In order to provide accurate readings that consider the current published ASTM standards, the contractor used an LTL-2000 handheld retroreflectometer and current ASTM procedures for handheld units in order to calibrate the Laserlux mobile reflectometer prior to each collection run. Each collection run consisted of a single road segment with segments being of varying lengths. Each segment was homogenous with respect to pavement marking material, material color, and road surface.

The retroreflectometer collected data using the standard 30-meter geometry by applying a $1 / 3$ scale that measures approximately $10-\mathrm{m}$ ahead of the vehicle. Figure 7 shows how a scanning laser measured a 42 " wide swath that collected retroreflectivity values at a rate of 100 readings per second at a speed of 60 miles per hour. This equates to approximately 600 data points for a tenth mile road segment, which in turn translates to approximately 1 data reading for every 11 inches. The computer was set to collect values only within a given $\mathrm{R}_{\mathrm{L}}$ range. This enabled the computer to recognize very large or very small values and remove them from the recorded data used to calculate the average retroreflectivity value for the road segment. An example of a low value would be from a section of unmarked pavement. The computer would recognize that this value is outside the preset range and discard it. Reflective raised pavement markers would be an example of something that would return an especially high $\mathrm{R}_{\mathrm{L}}$ value and again the computer would discard this value as well.

The dashed lines in Figure 7 illustrate the collection path of the laser as the vehicle travels down the road segment (upward in the figure) and the laser sweeps across the pavement (shown as left to right in the figure) collecting retroreflectivity values. The dash lines are arced because the laser swings from one side to the other while the vehicle is traveling at highway speeds. The laser then resets and starts the next collection sweep from the same side proceeding in the same direction for each sweep. 


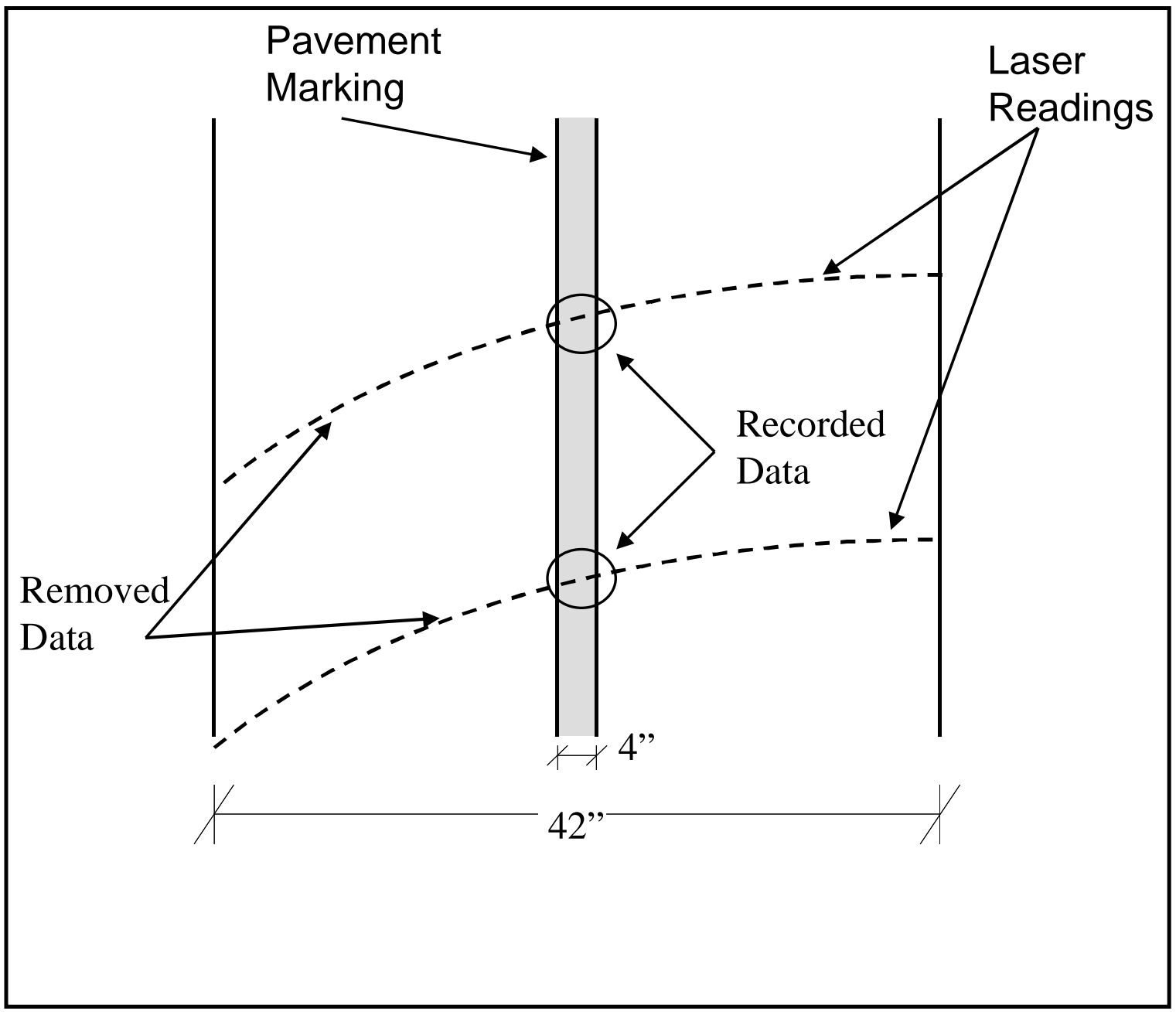

Figure 7. Data Collecting Laser

The $\mathrm{R}_{\mathrm{L}}$ readings are averaged for every tenth of a mile and recorded into the onboard computer. Additionally, a continuous average was recorded throughout the entire roadway segment using all the valid data points that were determined to lie on the pavement marking. The $\mathrm{R}_{\mathrm{L}}$ value has units of $\mathrm{mcd} / \mathrm{m}^{2} / \mathrm{lx}$ and is an average of all the valid scans recorded for a tenth-mile road segment. For a tenth-mile road segment there were approximately 600 data points evaluated but nearly 83 percent of the data are rejected because these values fell outside the preset range. This ensured only $R_{L}$ values for pavement markings were recorded and not the background $\mathrm{R}_{\mathrm{L}}$ for the road surface or for raised reflective pavement markers.

The vehicle was set up so that a single person can operate the vehicle and collect the data simultaneously. The operator was able to record any significant events using an event recorder that adds pre-designated codes to the data fields of the roadway segment. Significant events are those that might affect the meaning or interpretation of the data. Examples of event codes are roadway construction, intersections, or new paint. In addition to inputs from the Laserlux instrument and operator, a vehicle-mounted video camera recorded the entire data collection run for each segment. There is also a GPS 
device mounted in the vehicle and integrated into the onboard computer, which records the position data in the database at appropriate intervals.

Vehicle-mounted devices are subject to errors from variations in the suspension and roadway. However, the calibration process used throughout data collection minimized these precision errors. As part of a six-vehicle fleet, each LaserLux unit was calibrated on a known test bed of pavement markings at the fleet's maintenance facility. The test bed was comprised of pavement markings with known retroreflectivity values that were calculated using the LTL-2000. Having a known test bed enabled the maintenance crews to calibrate each unit to a known standard as well as to each other. The calibration process accounted for errors due to changes in vehicle load, tire pressure, and ambient light.

The LTL-2000 was also used in the field during collection operations. During field collection, the technicians measured the retroreflectivity of the test section at random points using an LTL-2000 and then calibrated the mobile unit using that same test section with the known retroreflectivity. Daily calibration accounted for local climate changes and minimized errors that may result from temperature and humidity.

\section{Data Reduction}

For purposes of this paper, a road segment is defined as a portion of a road of varying length on which the base material, pavement marking system, and marking color are uniform and continuous. Segments measured in this study varied in length from 4 to 50 miles. The retroreflectometer took continuous readings while the vehicle was in motion and filtered out any invalid readings. All valid readings were averaged for every tenth mile and the average value recorded in the database. An overall average was then computed for each road segment. Segments were measured initially within 30 days of application of the pavement marking, then again after six months, and finally one year after application. Further readings were taken annually for five years, so that there were seven data points between the initial observation and the five-year mark.

Due to the ongoing nature of the data collection, only some of the road segments had a full compliment of data and most roads had been under observation for some period less than five years. As will be discussed further below, this fact limited the options for statistical analysis. Data received from the NCDOT consisted of retroreflectivity measurement for over 800 road segments in NC.

Analysis was only conducted on those roads that used molten thermoplastic pavement markings. Molten thermoplastics is a long-life pavement marking material that is a blend of solid materials that become liquid when heated and then return to a solid state when cooled. While paints are the most common marking material in $\mathrm{NC}$ and elsewhere, they are considered to be non-durable. NCDOT uses an annual cycle for remarking with paint. This means most of these segments were repainted multiple times during the study. Since this study took measurements annually, the recorded data for painted markings was not used to model the degradation process. Painted markings need to be observed on a monthly basis for 12 months for valid data. Thus roads with painted 
markings were removed from the analysis and only thermoplastic markings were analyzed.

There were approximately 2,400 miles of measured roadway using thermoplastics markings for which data was available for study. Because thermoplastics are not commonly used on concrete, all of the road segments in this study had an asphalt surface course. Therefore, both marking material and pavement surface material were held constant during the analysis. Data were collected on both yellow and white colored pavement markings. Because these two colors have initial retroreflectivity values that are typically different and because they both degrade at different rates [Sarasua, et al], analysis was conducted separately on each color.

Lateral line locations were categorized as either center or edge lines. Centerlines include both center solid lines and center skip lines. To ensure valid conclusions, comparisons were only made between center and edge lines of identical color. Thus white edge lines were compared to white skip lines and yellow edge lines were compared to yellow centerlines.

\section{Average Value Analysis}

To conduct an initial analysis, the data set on thermoplastics was reduced to only those points that had a full five years of data available. This dramatically reduced the size of the data set, but still left enough road segments to conduct the analysis. The number of segments for which data was usable was as follows:

- Yellow center lines versus yellow edge lines (28 versus 8 road segments)

- White skip lines versus white edge lines (14 versus 6 road segments)

Even with the reduced data set, this still represented 419 miles of roadway with white markings and 210 miles of roadway with yellow marking. For each measurement time period (time $=0$ to 5 years), the average $\mathrm{R}_{\mathrm{L}}$ value was computed as:

$$
\mathrm{RL}_{\mathrm{ave}}=\left[\sum\left(\mathrm{RL}_{\mathrm{i}}\right)\right] /\left[\mathrm{N}_{\mathrm{t}}\right]
$$

where

$\mathrm{RL}_{\mathrm{ave}}=$ average retroreflectivity for each time period in $\mathrm{mcd} / \mathrm{m}^{2} / \mathrm{lx}$

$\mathrm{RL}_{\mathrm{i}}=$ measured retroreflectivity of road segment $i$ in $\mathrm{mcd} / \mathrm{m}^{2} / \mathrm{lx}$

$\mathrm{N}_{\mathrm{t}} \quad=$ number of road segments measured for each category \& time period.

A weighted average analysis was also conducted where the data was weighted based on the length of the road segment measured. Because the road segments did not have a uniform length, it is possible that the variation in segment length could skew the average value analysis. Road segments varied in length from 4 to 32 miles, with an average value of approximately 11 miles. The weighted analysis was conducted to determine if segment length affected the outcome of the analysis in any way. For each measurement time period (time $=0$ to 5 years) the average weighted $R_{L}$ value was computed using an weighted average value method such that: 


$$
\mathrm{RL}_{\mathrm{ave}}=\left[\sum\left(\mathrm{RL}_{\mathrm{i}} * \mathrm{~L}_{\mathrm{i}}\right)\right] /\left[\sum \mathrm{L}_{\mathrm{i}}\right]
$$

where

$\mathrm{RL}_{\mathrm{ave}}=$ average retroreflectivity for each time period in $\mathrm{mcd} / \mathrm{m}^{2} / \mathrm{lx}$

$\mathrm{RL}_{\mathrm{i}}=$ measured retroreflectivity of road segment $i$ in $\mathrm{mcd} / \mathrm{m}^{2} / \mathrm{lx}$

$\mathrm{L}_{\mathrm{i}} \quad=$ length of road segment $i$ in miles

$\sum \mathrm{L}_{\mathrm{i}} \quad=$ sum of all road segment lengths in miles

\section{Analysis of Variance}

The average value analysis described above determined only that there may be a difference in the rates of retroreflectivity degradation based on lateral line location. But an ANOVA can accurately establish whether or not that difference is statistically significant. Analysis of variance (ANOVA) is a statistical procedure for determining whether the difference between two sample means is statistically significant. The procedure looks at the variance within the two populations to see if the difference between their respective means is due to normal variance within the groups or if it is due to a true difference between the two populations.

The null hypothesis $\left(\mathrm{H}_{0}\right)$ stated that the difference between the centerline mean and the edge line mean was statistically insignificant. The alternative hypothesis $\left(\mathrm{H}_{\mathrm{a}}\right)$ stated that the difference in the means between centerline and edge line was statistically significant. A probability of F-value less than $\alpha=0.05$ indicates that the null hypothesis should be rejected in favor of the alternative hypothesis and that the difference between the two means is statistically significant.

This approach was important because it allowed the use of all available data sets, not just those that had been under observation for five years. Due to the ongoing nature of the data collection activity, many of the road segments had been under observation for less than a full five years. Average value analysis as described above was only valid for comparing sets that had all been under observation for the entire time. ANOVA compares the data at a certain time interval to all the other data at the same time interval, allowing the use of road segments that had been under observation for less than a full five years to be studied. This meant that the sample size was different at each time interval and decreased as time went on.

Using all the available data on thermoplastic markings an ANOVA analysis was conducted at each time period for all data available at that time period. All the initial measurements (that is, time $=0$ ) of yellow centerlines were compared to all the initial measurements of all yellow edge lines. Then the comparison was run at each successive time period using all available data in each time period. Because of the nature of the available data, the number of points analyzed was smaller in each successive time period. For both yellow and white markings, only about 25 percent of the total road segments had a full five years of data available. However, there were still enough road segments measured for a full five years that the results are considered to be sufficiently representative. 
The ANOVA analysis used data from approximately 2,414 miles of NC roads out of a total of approximately 78,000 miles of primary and secondary roads. Thermoplastics markings are used on 22.7 percent of these roads, meaning that there are approximately 19,500 miles of road in NC marked with thermoplastics. Thus our sample size of 2,414 miles of road comprised approximately 12 percent of roads marked with thermoplastics. We consider this to be a sufficiently large enough sample size from which to draw our conclusions.

As previously mentioned, the road segments used for the study were not uniform in length, varying from 4 to 32 miles with an average value of 11 miles. To account for this variation, the ANOVA analysis was conducted a second time with values weighted according to the length of the measured road segment. This analysis was initiated to determine if there was any bias in the first ANOVA due to excessively long or short road segments.

\section{RESULTS}

This section presents the results of the data analysis. Table 4 shows an overall summary of the statistics for all of the data points used in the analysis. Next, the average value results are shown and then followed by the ANOVA results. Finally, these results are compared to those reported in previous literature.

\section{Overall Summary Statistics}

Table 4 shows the overall summary statistics for the data collected, which are thermoplastics on asphalt. The first column is time given in months. Columns two, three, and four are the average retroreflectivity value, standard deviation, and range of values all given in $\mathrm{mcd} / \mathrm{m} 2 / \mathrm{lx}$.

Table 4. Summary Statistics for Thermoplastics on Asphalt

\begin{tabular}{||c|c|c|c||}
\hline Time (months) & $\begin{array}{c}\text { Mean RL } \\
(\mathrm{mcd} / \mathrm{m} 2 / \mathrm{lx})\end{array}$ & $\begin{array}{c}\text { Standard Deviation } \\
(\mathrm{mcd} / \mathrm{m} 2 / \mathrm{lx})\end{array}$ & $\begin{array}{c}\text { Range of Values } \\
(\mathrm{mcd} / \mathrm{m} 2 / \mathrm{lx})\end{array}$ \\
\hline \hline 0 & 365 & 103 & $168-563$ \\
\hline 6 & 324 & 82 & $201-473$ \\
\hline 12 & 319 & 85 & $163-488$ \\
\hline 24 & 235 & 75 & $110-443$ \\
\hline 36 & 212 & 67 & $93-383$ \\
\hline 48 & 223 & 62 & $88-364$ \\
\hline 60 & 222 & 75 & $98-389$ \\
\hline
\end{tabular}

\section{Average Value Analysis (Un-weighted)}

The un-weighted average value analysis showed that there was a difference in the degradation rates of center and edge lines for both white and yellow markings. Figure 8 and Table 5 show the results from the analysis of yellow thermoplastics. As expected 
both center line and edge line show an initial drop in retroreflectivity in the first two years and then show a much shallower, or even a flat curve beyond that. The two curves do not start at the exact same initial value due to the fact that they represent two averages of all centerlines and edges lines, and they are not matched pairs on the exact same group of road segments. The two curves are roughly parallel but the somewhat faster degradation in the centerline curve is visible. The third data series and trend line at the bottom of the chart shows the delta (difference) between the two average measurements at each time period. This trend line has a positive slope, indicating that the delta is increasing over time and therefore the two groups are degrading at different rates.

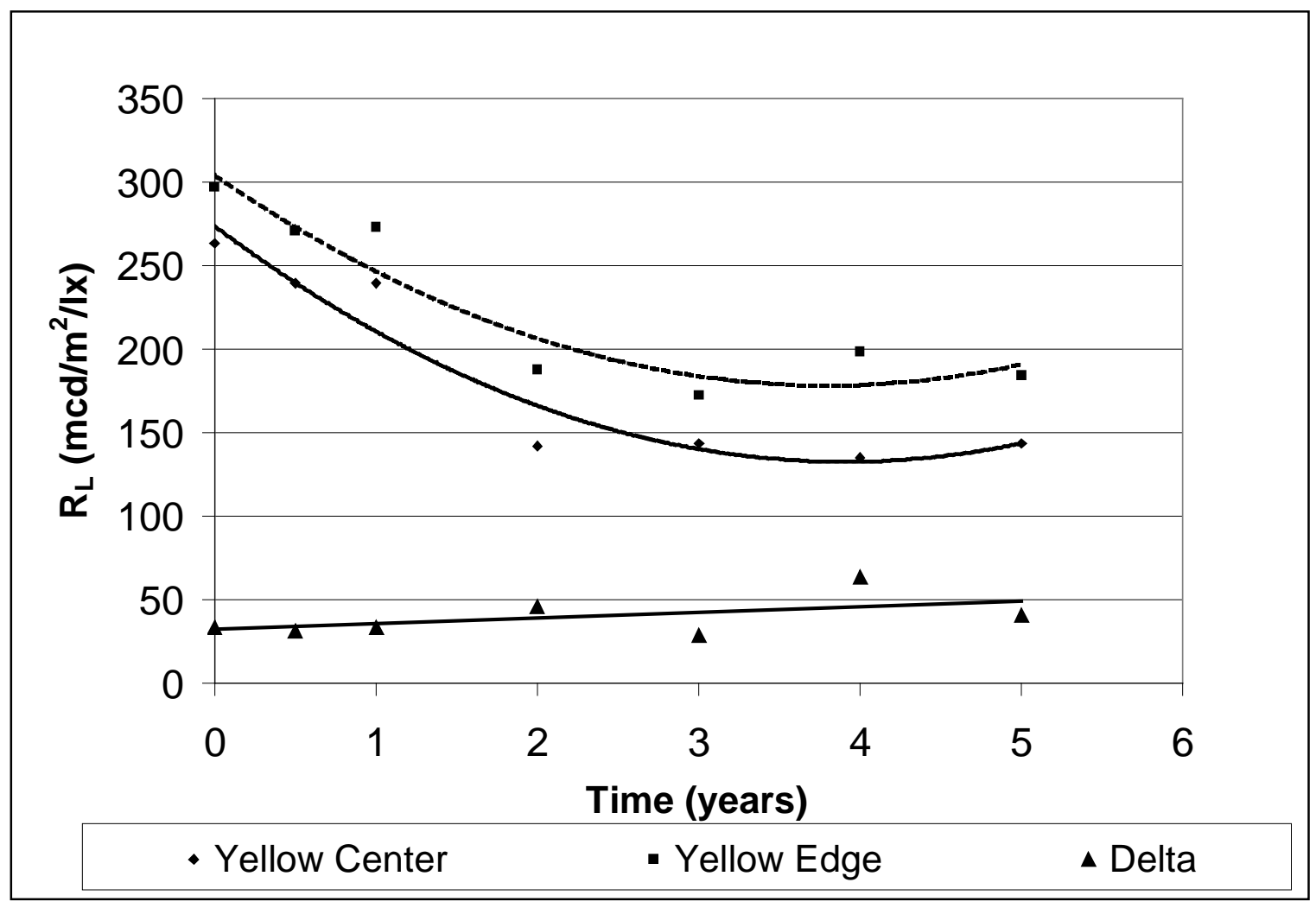

Figure 8. Average RL Values Over Time of Yellow Thermoplastics (Un-weighted)

Table 5. Average $\mathbf{R}_{\mathrm{L}}$ Values Over Time of Yellow Thermoplastics (Un-weighted)

\begin{tabular}{||l||c|c|c|c|c|c|c||}
\hline \hline TIME (years) & $\mathbf{0}$ & $\mathbf{0 . 5}$ & $\mathbf{1}$ & $\mathbf{2}$ & $\mathbf{3}$ & $\mathbf{4}$ & $\mathbf{5}$ \\
\hline \hline Yellow Edge & 297 & 271 & 273 & 188 & 173 & 199 & 184 \\
\hline Yellow Center & 263 & 240 & 240 & 142 & 144 & 135 & 144 \\
\hline Delta & 34 & 31 & 33 & 46 & 29 & 63 & 41 \\
\hline
\end{tabular}

** Values given in $\mathrm{mcd} / \mathrm{m}^{2} /$ lux 
The results from the comparison of white edge lines to white skip lines are shown in Figure 9 and Table 6. Similar to the yellow thermoplastics, the two curves show a difference in the rate of degradation, but this difference is more pronounced. In this case, the average value for white skip lines starts out higher than for edge lines at the initial observation, yet after five years the skip lines have a lower value, indicating a larger difference in degradation rate. The delta data series and trend line at the bottom of the chart shows the difference between the measurements at each time period. Similar to yellows thermoplastics, this trend line has a positive slope, indicating that the degradation rates between the edge and skip lines are different.

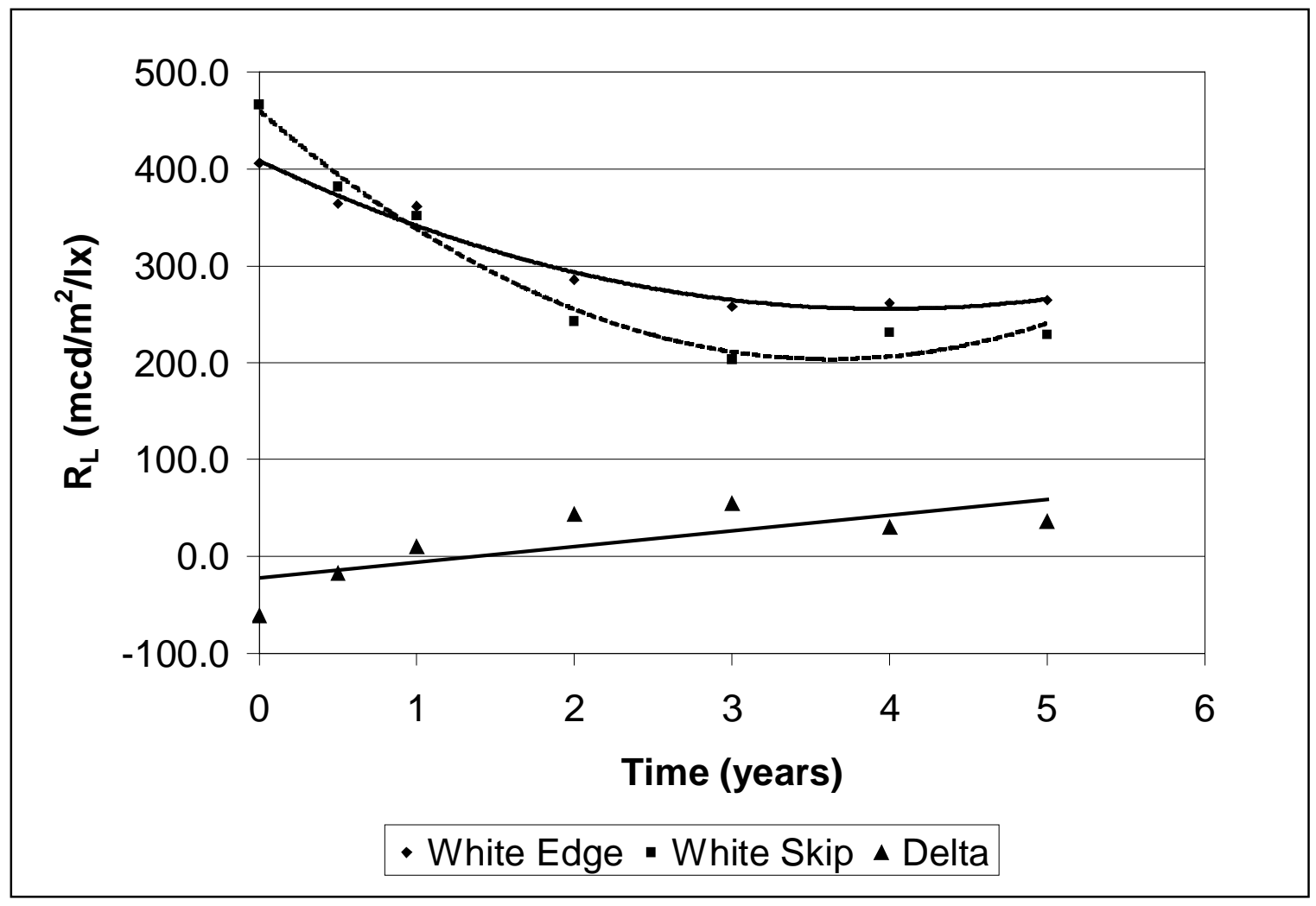

Figure 9. Average RL Values Over Time of White Thermoplastics (Un-weighted)

Table 6. Average $\mathbf{R}_{\mathrm{L}}$ Values Over Time of White Thermoplastics (Un-weighted)

\begin{tabular}{||l||c|c|c|c|c|c|c||}
\hline TIME (years) & $\mathbf{0}$ & $\mathbf{0 . 5}$ & $\mathbf{1}$ & $\mathbf{2}$ & $\mathbf{3}$ & $\mathbf{4}$ & $\mathbf{5}$ \\
\hline \hline Yellow Edge & 406 & 364 & 362 & 286 & 258 & 261 & 265 \\
\hline Yellow Center & 467 & 382 & 352 & 242 & 204 & 231 & 229 \\
\hline Delta & -61 & -18 & 10 & 44 & 54 & 30 & 36 \\
\hline \hline
\end{tabular}

** Values given in $\mathrm{mcd} / \mathrm{m}^{2} / \mathrm{lux}$

\section{Average Value Analysis (Weighted)}

The weighted average analysis produced results very similar to the un-weighted analysis. Figure 10 and Table 7 show the retroreflectivity degradation of yellow thermoplastics weighted to account for variation in length of road segments. This curve is nearly 
identical to the un-weighted analysis for yellow thermoplastics shown in Figure 8. Both center and edge lines show an initial drop in retroreflectivity in the first two years of service and then exhibit a flat curve beyond that point. The delta data series shows the difference between two averages at each time interval. Its trend line shows a positive increase over time, indicating that the centerlines are degrading at a higher rate than the edge lines. Additionally, the weighted trend line shows a much steeper slope than the trend line in the un-weighted trend line in Figure 8. This means that the difference between the lateral locations is more pronounced in this analysis.

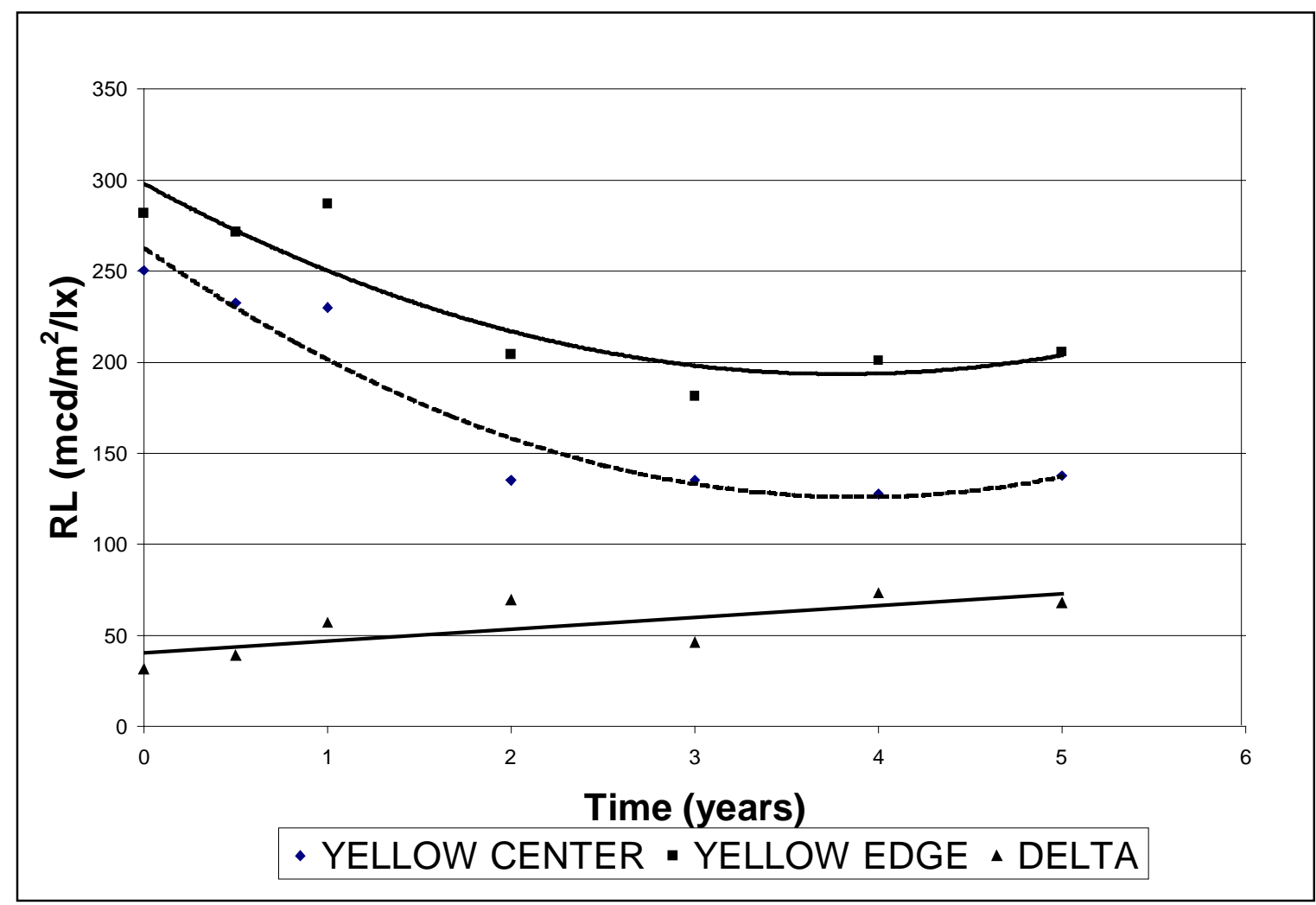

Figure 10. Average Value Over Time of Yellow Thermoplastics (Weighted by Length)

Table 7. Average $\mathbf{R}_{\mathbf{L}}$ Values Over Time of Yellow Thermoplastics (Weighted by Length)

\begin{tabular}{||l||c|c|c|c|c|c|c||}
\hline \hline TIME (years) & $\mathbf{0}$ & $\mathbf{0 . 5}$ & $\mathbf{1}$ & $\mathbf{2}$ & $\mathbf{3}$ & $\mathbf{4}$ & $\mathbf{5}$ \\
\hline \hline Yellow Edge & 282 & 272 & 287 & 205 & 181 & 201 & 206 \\
\hline Yellow Center & 251 & 233 & 230 & 135 & 135 & 128 & 138 \\
\hline Delta & 31 & 39 & 57 & 69 & 46 & 73 & 68 \\
\hline
\end{tabular}

Figure 11 and Table 8 show the retroreflectivity degradation of white thermoplastics weighted to account for variation in length of road segments. Again, this curve is very similar to the curves shown in the un-weighted analysis of white thermoplastics shown in 
Figure 9. Both skip and edge lines showed the initial drop in retro reflectivity in the first two years and then show a much shallower degradation rate. Additionally, as in Figure 9 the white skip lines starts with a higher initial average than white edge lines, but the two curves cross, indicating the skip line is degrading at faster rate than the edge line. Finally the trend line of the delta exhibits a positive slope, confirming that the skip line has

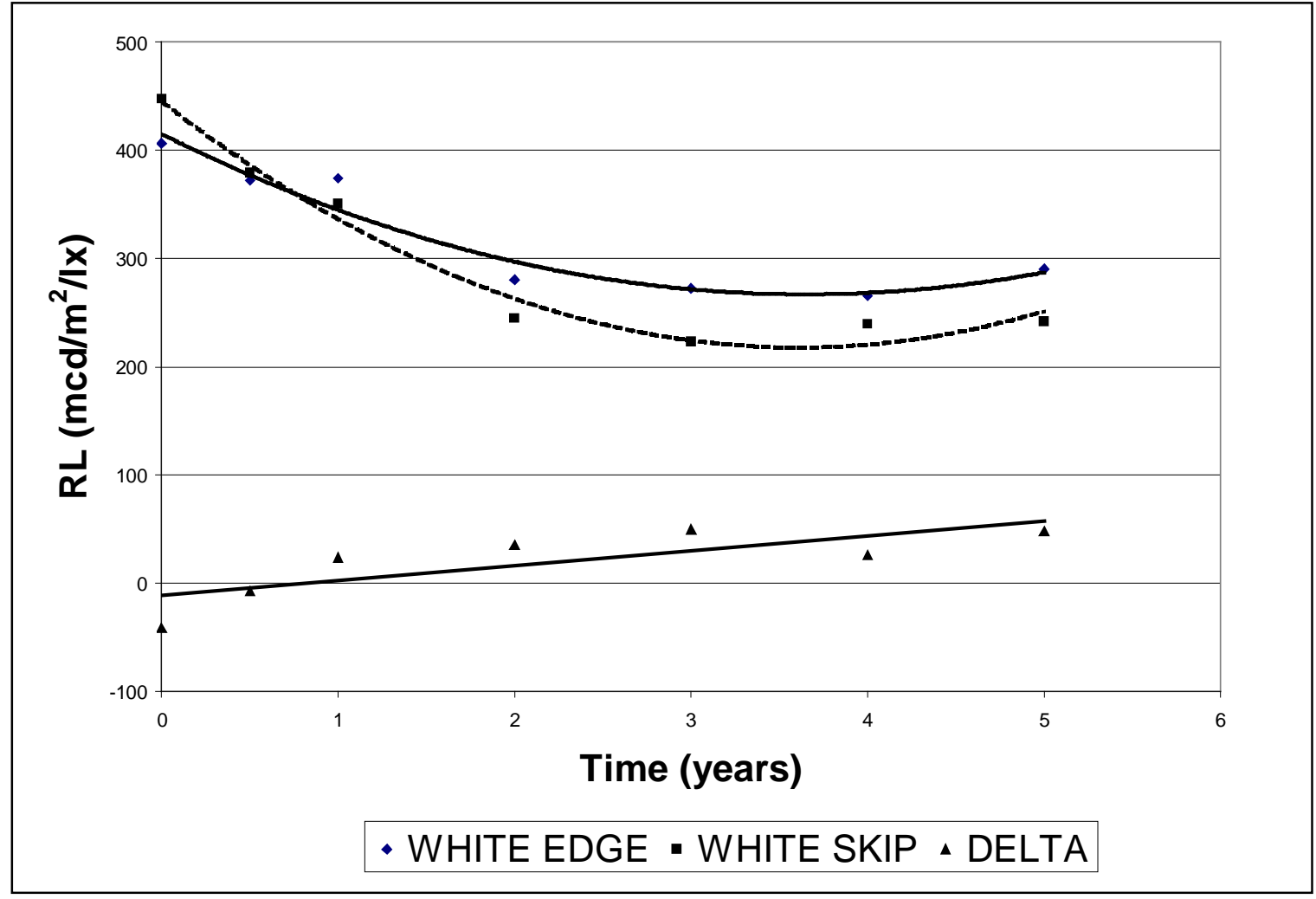

degraded faster.

Figure 11. Average Value Over Time of White Thermoplastics (Weighted by Length)

Table 8. Average $R_{L}$ Values Over Time of White Thermoplastics (Weighted by Length)

\begin{tabular}{||l||c|c|c|c|c|c|c||}
\hline \hline TIME (years) & $\mathbf{0}$ & $\mathbf{0 . 5}$ & $\mathbf{1}$ & $\mathbf{2}$ & $\mathbf{3}$ & $\mathbf{4}$ & $\mathbf{5}$ \\
\hline \hline White Edge & 406 & 372 & 374 & 280 & 272 & 266 & 290 \\
\hline White Skip & 448 & 379 & 351 & 245 & 223 & 240 & 242 \\
\hline Delta & -41 & -7 & 24 & 35 & 49 & 26 & 48 \\
\hline
\end{tabular}

** Values given in $\mathrm{mcd} / \mathrm{m}^{2} /$ lux

Both the un-weighted and weighted methodologies produced very similar results in this analysis. The two methods confirm the results of each other, and also indicate that weighting the data based on varying road segment has little effect on the outcome. For both colors, edge lines appear to degrade at a slower rate than center or skip lines. 
The trend patterns seen in Figures $8-11$ show a slight increase in retroreflectivity as the material aged. The trend patterns were shown to give the reader an indication of the gap between retroreflectivity at different lateral line locations. These figures do not show a pattern of degradation. The difference in retroreflectivity, as it relates to the lateral location, is the key trend of concern and clearly shows the gap increasing over time. This confirms that lateral location impacts the rate of degradation. The small upward trend seen in the pattern is most likely from variations in the data collection device.

\section{Analysis of Variance (Un-weighted)}

The ANOVA analysis was performed using the following null and alternative hypotheses:

- $\mathrm{H}_{0}$ Null Hypothesis: The difference between the centerline mean and the edge line mean was statistically insignificant such that $\left[\mathrm{R}_{\mathrm{L}}\right.$ degradation of edge lines] = $\left[\mathrm{R}_{\mathrm{L}}\right.$ degradation of center lines] for all time periods.

- $\mathrm{H}_{\mathrm{a}}$ Alternative Hypothesis: The difference between the centerline mean and edge line mean was statistically significant such that $\left[\mathrm{R}_{\mathrm{L}}\right.$ degradation of edge lines $] \neq$ $\left[\mathrm{R}_{\mathrm{L}}\right.$ degradation of center lines] for all time periods.

If the F-value from the analysis is less than or equal to the level of significance of $\alpha=$ 0.05 , this indicates there is sufficient statistical proof to reject the null hypothesis in favor of the alternative hypothesis. The results of the analysis are shown in Table 9. Values below .05 are highlighted in dark grey and those values between .05 and .1 are highlighted in light grey.

TABLE 9. ANOVA F-test results for white \& yellow thermoplastics (Un-weighted)

\begin{tabular}{||l||c|c|c|c|c|c|c||}
\hline & INITIAL & $\begin{array}{c}\mathbf{6} \\
\text { MONTHS }\end{array}$ & $\begin{array}{c}\text { YEAR } \\
\mathbf{1}\end{array}$ & $\begin{array}{c}\text { YEAR } \\
\mathbf{2}\end{array}$ & $\begin{array}{c}\text { YEAR } \\
\mathbf{3}\end{array}$ & $\begin{array}{c}\text { YEAR } \\
\mathbf{4}\end{array}$ & YEAR 5 \\
\hline \hline $\begin{array}{l}\text { White Edge vs. } \\
\text { White Skip Lines }\end{array}$ & 0.5426 & 0.0001 & 0.0001 & 0.0003 & 0.0687 & 0.0778 & 0.0625 \\
\hline $\begin{array}{l}\text { White Sample } \\
\text { Sizes } \\
\text { (Edge /Skip) }\end{array}$ & $115 / 78$ & $111 / 88$ & $\begin{array}{c}105 / \\
80\end{array}$ & $73 / 61$ & $46 / 32$ & $32 / 20$ & $30 / 18$ \\
\hline $\begin{array}{l}\text { Yellow Edge vs. } \\
\text { Yellow Center } \\
\text { Lines }\end{array}$ & 0.3718 & 0.1053 & 0.0875 & 0.0866 & 0.0595 & 0.0041 & 0.0529 \\
\hline $\begin{array}{l}\text { Yellow Sample } \\
\text { Sizes } \\
\text { (Edge /Center) }\end{array}$ & $59 / 37$ & $59 / 38$ & $55 / 36$ & $47 / 16$ & $29 / 10$ & $20 / 6$ & $18 / 6$ \\
\hline
\end{tabular}

Both comparisons show a statistically insignificant difference in the initial time period (0.5426 and 0.3718), as expected. Ideally edge lines and centerlines marked at approximately the same time would have similar $\mathrm{R}_{\mathrm{L}}$ values. Since this is not a matched 
paired analysis (where we are comparing center lines and edge lines from the same road segment) it is expected that there will be some variation between the two population means. For white markings, there is an extremely significant difference between edge and skip lines between six months and two years (0.0001 to 0.0003). Because most of the degradation is expected to occur during this time period, it makes sense that these time periods would show the most significant difference in degradation. For three to five years, some of the values are out side of the 95 percent level of significance criteria (0.0625 to 0.0778 ) but remain close enough to indicate a high level of confidence that there is a statistically significant difference.

For yellow markings, the six-month comparison is just below the 90 percent confidence mark with an F-value of 0.1053. From year one through year three and again in year five, the F-values indicate that there is greater than 90 percent chance that edge and center lines have degraded at different rates. Year four exhibits a 99 percent certainty that the difference in the two group means is statistically significant.

\section{Analysis of Variance (Weighted)}

The ANOVA procedure shown above was repeated with the average values weighted according to the length of the individual road segments. The results of the analysis are shown in Table 10. Values below 0.05 are considered to be statistically significant and are highlighted in dark grey. Those values between 0.05 and 0.1 indicate a close proximity to the 95 percent level of confidence and are highlighted in light grey.

TABLE 10. ANOVA F-test results for white \& yellow thermoplastics (Weighted)

\begin{tabular}{||l||c|c|c|c|c|c|c||}
\hline & INITIAL & $\begin{array}{c}\mathbf{6} \\
\text { MONTH } \\
\mathbf{S}\end{array}$ & YEAR 1 & $\begin{array}{c}\text { YEAR } \\
\mathbf{2}\end{array}$ & $\begin{array}{c}\text { YEAR } \\
\mathbf{3}\end{array}$ & $\begin{array}{c}\text { YEAR } \\
\mathbf{4}\end{array}$ & YEAR 5 \\
\hline \hline $\begin{array}{l}\text { White Edge vs. } \\
\text { White Skip } \\
\text { Lines }\end{array}$ & 0.0363 & 0.0035 & 0.0009 & 0.1383 & 0.1363 & 0.0738 & 0.0754 \\
\hline $\begin{array}{l}\text { White Sample } \\
\text { Sizes } \\
\text { (Edge /Skip) }\end{array}$ & $740 / 433$ & $736 / 550$ & $709 / 512$ & $\begin{array}{c}575 / \\
433\end{array}$ & $\begin{array}{c}457 / \\
331\end{array}$ & $\begin{array}{c}326 / \\
209\end{array}$ & $302 / 185$ \\
\hline $\begin{array}{l}\text { Yellow Edge vs. } \\
\text { Yellow Center } \\
\text { Lines }\end{array}$ & 0.2828 & 0.1474 & 0.1126 & 0.0302 & 0.0143 & 0.0007 & 0.0032 \\
\hline $\begin{array}{l}\text { Yellow Sample } \\
\text { Sizes } \\
\text { (Edge /Center) }\end{array}$ & $415 / 184$ & $434 / 180$ & $412 / 174$ & $\begin{array}{c}371 / \\
116\end{array}$ & $\begin{array}{c}308 / \\
86\end{array}$ & $\begin{array}{c}209 / \\
58\end{array}$ & $185 / 59$ \\
\hline
\end{tabular}

The data for white thermoplastics indicate that there are statistically significant differences between the edge and skip line populations. The initial, 6-month, and 1-year periods have F-values less than 0.05 , indicating the two populations are clearly different. It also shows very low F-values throughout the rest of the series, indicating an 85 percent or greater confidence level that the two populations exhibit a different rate of degradation. The low F-value at the initial reading is contrary to what we would expect, 
since ideally both the edge and center lines should have very nearly identical retroreflectivity values when the are first placed. However this analysis is conducted using two large populations, and this aberration is most likely due to normal variations in the two respective populations. As will be discussed in the recommendations, a matched pair analysis, comparing center and edge lines on the same road segment, would account for this variation.

Yellow thermoplastics also exhibit a statistically significant difference in degradation rates. As expected, the initial F-value is high, indicating that any difference between the two populations is due to normal variance within the populations. The F-value decreases steadily with time, and reaches the 95 percent confidence level at the 2-year through 5year mark. This indicates that by year two, the edge and centerline populations are exhibiting clearly different rates of degradation.

\section{Comparison to Current Literature}

The degradation curves observed in this study generally follow those established in the South Carolina study as shown in Figure 6. The NCSU study curves do not exhibit the initial increase in retroreflectivity shown in the South Carolina curves. This is most likely due to the longer observation interval used in this study. South Carolina took monthly measurements for its test, whereas this study's data were collected at 6-month and 1-year intervals. It is likely the initial increases occurred but were no longer evident at the six-month mark.

The average length of service life for thermoplastics in this study are longer than those estimated by Migletz, et al. all (2001). Migletz stated that the average service life for thermoplastics was a little over two years (See Table 3). However, all the road segments that were observed for five years in this study had a retroreflectivity greater than 100 $\mathrm{mcd} / \mathrm{m}^{2} / \mathrm{lux}$ and were still considered to be serviceable.

\section{CONCLUSIONS}

There is clear statistical evidence that shows a difference in the rate of retroreflectivity degradation between edge lines and centerlines for both yellow and white thermoplastic markings. The data was analyzed using four different methodologies, which all consistently showed a difference in the degradation rates between edge lines and center or skip lines. Both weighted and un-weighted average value analysis showed nearly identical results and indicated that edge lines degrade at a slower rate than center or skip lines for both white and yellow thermoplastics.

Additionally, both the un-weighted and weighted ANOVA analysis indicate that there is a consistent 85 percent or greater probability that edge lines and center lines degrade at different rates from six months through five years for both yellow and white thermoplastic markings. In most cases the level of significance is above 90 percent and reaches as much as 99 percent. For both white and yellow thermoplastics, the available data set supports the conclusion that centerline degrade more rapidly than edge lines from six months to five years. All four methodologies used to analyze the data are considered 
to be equally valid approaches. The fact that all four methods reached the same conclusion is a good indication that the conclusion is accurate.

All of the road segments observed for a full five years were still serviceable at the end of the observation period with an average retroreflectivity value above $100 \mathrm{mcd} / \mathrm{m}^{2} / \mathrm{lux}$. Formerly the service life of thermoplastics was thought to be approximately two years [Migletz et. all 2001], but the data presented herein indicate that service life for NC may actually be much longer.

\section{RECOMMENDATIONS}

This study would suggest that a change in asset management practices by state departments of transportation might be in order. Because edge lines degrade at a slower rate than the centerlines or skip lines, there is a potential cost savings in replacing edge lines less frequently than center or skip lines. Discussions with NCDOT officials confirmed that typically a contractor will only lay pavement marking on a single lateral location at a time in a rolling operation, and must make multiple passes over the road to mark both edge and center lines. This means that the expense of mobilizing two separate times should not outweigh the savings of marking edge lines only half as often, especially considering that there are typically two edge lines for every center line for both primary and two-lane roads, which make up the vast majority of the road network in NC and elsewhere.

A second recommendation is that state departments of transportation should initiate welldesigned and controlled studies of their pavement markings. The data available for the NCSU study was limited to pavement markings that have been under observation for five years or less. After five years of service, both yellow and white markings had $\mathrm{R}_{\mathrm{L}}$ values in the range of 150 to $300 \mathrm{mcd} / \mathrm{m}^{2} / \mathrm{lux}$, which is still well above the proposed federal minimum standards. Several more years of data are needed to accurately determine the point at which both edge and centerlines will degrade beyond their useful service life. This recommendation would provide both NCDOT and other state transportation departments with valuable data for future study and maintenance cycle planning.

Data should also be collected in matched pairs in order to compare edge and center lines from the same road segment over the same period of time. This would eliminate variations in the data due to weather, traffic, and material installation quality. We also recommend that the observation interval needs be much smaller than the yearly measurements used in this study. Measurements should be made monthly or quarterly to more accurately model the degradation over time. Finally, since all available road segments were still serviceable after five years, the total observation time needs to be between five and ten years in order to accurately determine the end of service life of the thermoplastic pavement markings.

Because they make up approximately 60 percent of all pavement markings in $\mathrm{NC}$ and other places, it may be worthwhile to conduct a similar analysis on both waterborne and solvent paints. Because paints are considered to be non-durable and are typically replaced on an annual basis, this analysis would require that data be collected on a monthly (or 
more frequent) basis to accurately determine the degradation rate. This data could be used to determine what difference, if any, exists between the retroreflectivity rates of painted edge and center lines, and whether or not this difference warrants changes in asset management and maintenance schedules for these lines.

A final recommendation from this study is to develop a pavement marking experimental facility that could be used to support long-term study of different pavement markings in a controlled environment. Making observations monthly for several years to assemble an accurate mathematical model of the degradation curve could compare various types, or even all types, of pavement markings. In addition, random samples of actual markings on carefully selected support roads located through out a state could be collected to factor in regional weather effects and the average daily traffic volume.

\section{REFERENCES}

Al-Masaeid, H. R. and Sinha, K. C. (1994). "Analysis of Accident Reduction Potential of Pavement Markings," Journal of Transportation Engineering, Vol. 120, No. 5, pages 723-736.

American Association of State Highway and Transportation Officials (AASHTO) (2004). A Policy on Geometric Design of Highways and Streets. $5^{\text {th }}$ Ed, AASHTO, Washington, D.C.

American Society for Testing Materials (ASTMa), (2005). "Standard Test Method for Measurement of Retroreflective Pavement Marking Materials with CEN-Prescribed Geometry Using a Portable Retroreflectometer." ASTM E 1710-05, American Society for Testing and Materials International, West Conshohoken, PA.

American Society for Testing Materials (ASTMb), (2005). "Standard Practice for Describing Retroreflection." ASTM E 808, American Society for Testing and Materials International, West Conshohoken, PA.

Baker, J.A., and Lambert, J.H. (2001). "Information System for Risks, Costs, and Benefits of Infrastructure Improvement Projects." Public Works Management and Policy, Vol. 5, No. 3, pages 198-208.

Cambridge Systems, Inc. (2002). “Transportation Asset Management Guide.” NCHRP Project 20-24(11), Transportation Research Board, Washington, D.C.

Howard, C. (2006). Interview with North Carolina State Department of Transportation Pavement Marking Engineer. 11 October 2006, Raleigh, N.C.

McDiarmid, M. (2001). "Mobile Pavement Marking Retroreflectometer Data Collection for TIP Project R-4067." Memorandum for Record March 8, 2001, State of NC Department of Transportation, Raleigh, NC. 
Migletz, J., Graham, J., Harwood, D.W., and Bauer, K.M. (2001). "Service Life of Durable Pavement Markings." Transportation Research Record 1749, TRB, National Research Council, Washington D.C., pages 13-21.

Migletz, J. and Graham, J. (2002). "NCHRP Synthesis 306 Long-term Pavement Marking Practices.” Transportation Research Board, Washington D.C.

Precision Scan, LLC. (2006). Website, www.precisionscan.com. Thomasville, NC

Sarasua, W. A., Clarke, D. B., and Davis, W. J. (2003). "Evaluation of Interstate Pavement Marking Retroreflectivity." Report to South Carolina Department of Transportation, Report No. FHWA-SC-03-01.

Texas Transportation Institute (2001). Summary of Evaluation Findings for 30 Meter Handheld and Mobile Pavement Marking Retroreflectometers. Draft Technical Evaluation Report, Highway Innovative Technology Evaluation Center, Civil Engineering Research Foundation, Washington D.C.

Turner, J. D., (1998). Pavement Marking Retroreflectivity: Research Overview and Recommendations. Unpublished Report to the Federal Highway Administration, Office of Safety and Traffic Operations, McLean, VA.

United States Congress (1993). United States Department of Transportation and Related Agency Appropriation Act of 1993. Washington GPO, Washington, D.C.

Vereen, S. C., Hummer, J. E., and Rasdorf, W. J. (2004). "Alternative Approaches for State Agencies to Address the Proposed Minimum Retroreflectivity Standards." Public Works Management and Policy, Vol. 8, No. 4, pages 235 -248.

Wilson-Orndoff, C. J. (2003). "Citizen-Based Priorities in Transportation." Public Works Management and Policy, Vol. 7, No. 4, pages 256-266. 